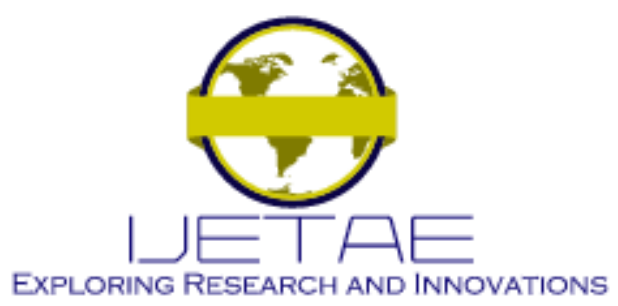

International Journal of Emerging Technology and Advanced Engineering

Website: www.ijetae.com (E-ISSN 2250-2459, Scopus Indexed, ISO 9001:2008 Certified Journal, Volume 11, Issue 12, December 2021)

Manuscript Received: 08 November 2021, Received in Revised form: 7 December 2021, Accepted: 12 December 2021

DOI: 10.46338/ijetae1221_09

\title{
Assessment for Nuclear Fuel Cycle Management in the Aspect of Security Using System Dynamic (SD) Method
}

\author{
Kyung Bae Jang ${ }^{1}$, Chang Hyun Baek ${ }^{2}$, Tae Ho Woo ${ }^{3}$ \\ ${ }^{1,2,3}$ Department of Mechanical and Control Engineering, The Cyber University of Korea, 106 Bukchon-ro, Jongno-gu, Seoul \\ 03051, Republic of Korea
}

\begin{abstract}
The security in the nuclear fuel cycle process has demonstrated that the behaviour of international terrorism is one of the nuclear industrial challenges where the complex algorithm of systems dynamics (SD) is applied. The simulation results are shown by graphs of the security of the nuclear fuel cycle which is related to the security scenarios of nuclear power plant (NPP). The simulation results have higher values, when the security is in worse situations. The importance of the study is the performance of dynamical simulation of the nuclear fuel cycle, the security incorporated with safeguard, and the 10 years' analysis.
\end{abstract}

Keywords - Security, Terrorism, Nuclear power plants, Safeguard, System dynamics, Simulation, Transmission, Cycle

\section{INTRODUCTION}

The security of the nuclear fuel cycle process and its related nuclear power plants (NPPs) are assessed by the dynamical manner. It is important to keep the safeguard of the nuclear fuel cycle in order not to produce any kinds of the nuclear bomb violating the nuclear non-proliferation treaty (NPT). The assessment is performed by the system dynamics (SD) as the dynamical analysis in this paper, which is the nonlinear complex algorithm. The nuclear fuels cycle and nuclear safeguards are considered simultaneously, which are inter-connected for the characteristics of the security. There is the nuclear security and safeguards analysis explained by nuclear regulatory commission (NRC) [1]. That is to say, the NRC ensures safeguards and security by regulating licensees' accounting systems for special nuclear and source materials, and security programs and contingency plans. These have the domestic safeguards, information security, radioactive material security, and contacting to us about public meetings on nuclear security and safeguards.
There are the sections 3(c) and (e) of the Atomic Energy Act of 1954 and section 204(b)(1) of the Energy Reorganization Act of 1974, which make NRC do the responsibility for ensuring that the peaceful uses of nuclear energy make the maximum contribution to the common defense, security, the national welfare, and so on provide continued assurance of the government's ability to enter into and enforce agreements with nations or groups of nations for the control of special nuclear material. The meaning of safeguards and security are generally used to describe programs that promote the common defense and security and protect public health and safety by guarding against theft and sabotage. The licensee security programs and contingency plans control with threats, thefts, and sabotage relating to special nuclear material, nuclear facilities, high-level radioactive wastes, and other radioactive materials and activities that the NRC regulates.

There were some security studies. Although there are several kinds of security studies for electricity, the main goal is to focus on the stabilized electricity supply. Perninge et al. [2] worked that to improve Monte Carlo simulation, many different contingency selection techniques had been proposed in the literature. Also, Trehan [3] said the electric utilities are under great pressure to maintain system security as the transmission system in North America is already operating closer to its stability limits. The limited construction of new transmission lines has pushed the power industry toward the development of advanced technologies that may improve the electrical grid security (stability) to some extent. In addition, Chen et al. studied that the work goes a step further by proposing a new method of forming a contingency list, based on substation configuration obtained from topology processing data and probability analysis of protection system failures. 


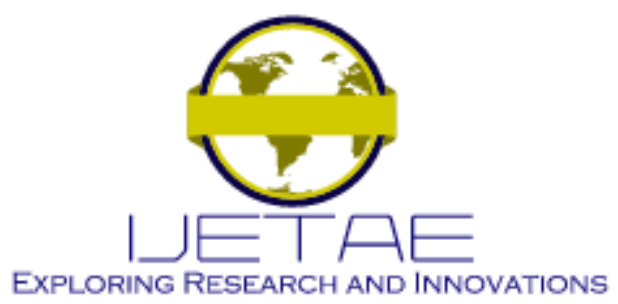

International Journal of Emerging Technology and Advanced Engineering

Website: www.ijetae.com (E-ISSN 2250-2459, Scopus Indexed, ISO 9001:2008 Certified Journal, Volume 11, Issue 12, December 2021)

This method is particularly suited for online security assessment [4]. Jun et al. [5] provided such metrics and apply them to four major energy sources in the Korean electricity market: coal, oil, liquefied natural gas, and nuclear. Finally, Salameh's paper examined the new frontiers of the United States' energy security in the $21^{\text {st }}$ century. It argued that fossil fuels would continue to dominate US energy needed well into the $21^{\text {st }}$ century and that the Gulf region would maintain its strategic importance for US energy security for the foreseeable future [6].

\section{Methodology}

\section{A. Nuclear fuel cycle}

The nuclear fuel cycle initiates from the mining of the uranium. It is impossible to use the uranium directly in NPPs, which is mined from earth. Most processing is performed by the concentration of the U-235 isotope. This has the distinctive and complicated cycle system of fuel. The fuel cycle has several steps as mining and milling, conversion, enrichment, and fuel fabrication. These steps are known as the 'front end' of the cycle. After producing the electricity, the uranium becomes the spent fuel. This goes to the 'back end' of the cycle which includes temporary storage, reprocessing, recycling, and waste disposal. Fig. 1 shows the simplified nuclear fuel cycle for International Atomic Energy Agency (IAEA) safeguards. There are some explanations in each step [7]. Those are Fuel mining (Uranium recovery to extract (or mine) uranium ore, and concentrate (or mill) the ore to produce 'yellowcake'), Conversion (Conversion of yellowcake into uranium hexafluoride $\left(\mathrm{UF}_{6}\right)$ ), Enrichment (Enrichment to increase the concentration of uranium-235 $\left(\mathrm{U}^{235}\right)$ in $\left.\mathrm{UF}_{6}\right)$, De-conversion (De-conversion to reduce the hazards associated with the depleted uranium hexafluoride (DU $\mathrm{F}_{6}$ ), or 'tailings,' produced in earlier stages of the fuel cycle), Fuel fabrication (Fuel fabrication to convert enriched $\mathrm{UF}_{6}$ into fuel for nuclear reactors), Fuel loading (Use of the fuel in reactors (nuclear power, research, or naval propulsion)), Intermediate Storage (Interim storage of spent nuclear fuel), Reprocessing (Reprocessing (or recycling) of highlevel waste (currently not done in the U.S.)), and Disposition (Final disposition (disposal) of high-level waste).

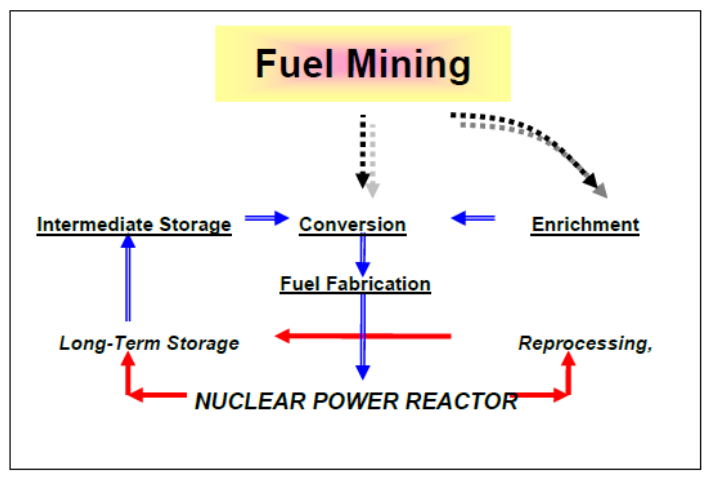

Fig. 1 Simplified nuclear fuel cycle for IAEA safeguards (single line : spent fuel flow, double line : low enrichment fuel flow, dotted line : yellow cake and natural uranium flow).

In the 'front end' of the cycle, the terror related incident could be happened in which the nuclear fuel material can be delivered to a suspicious group. The security system level of the raw material is comparatively lower in keeping the substance quality, because the material is not radioactive unless the nuclear reactions are not done. The nuclear reaction is initiated by the neutron, which is different from the conventional burning system in the oil and coal power plants of fire ignition system. So, the nuclear fuel material is controlled easily by hand which is called 'yellow cake', a yellow colored uranium compound material. Since a terrorist would like to seek the less security stage of the nuclear fuel cycle, this step is interested by the dangerous groups that have the plans for terror attack. Although the personnel don't have highly trained skills in nuclear and radioactive material controls, it is targeted by the terrorists. Hence, this stage should be controlled by the authorized agency or central government. Once the nuclear material is transferred to the gangster or terror group, the material fabrications would be processed. Although the very dangerous radiation could be produced, they would like to endure the dangerous situation to obtain the nuclear bomb which could be used in the terror incident.

In the 'back end' of the cycle, it is nearly impossible to make the reprocessing in the general nations following the nuclear nonproliferation treaty (NPT) where any country must not make the nuclear bomb except of 5 nations as United States, Russia, China, United Kingdom, and France. 


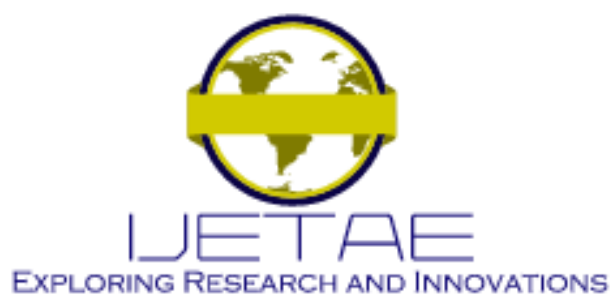

International Journal of Emerging Technology and Advanced Engineering

Website: www.ijetae.com (E-ISSN 2250-2459, Scopus Indexed, ISO 9001:2008 Certified Journal, Volume 11, Issue 12, December 2021)

If a certain country would like to break the above fact, it is inevitable to punish by the countries including peaceful or armed intervention. So, the nuclear reprocessing for collecting the nuclear material for bomb manufacturing could provoke the international pressure to give up the nuclear reprocessing. Hence, the secrete working by a group or a nation would be censored by the satellite systems. For example, the geostationary orbit can be used to seek the nuclear experiment site in the space where the highly qualified resolution attached detection system should find out the strange task on the ground. Nuclear test produces the radioactive material of the Xenon isotopes. Therefore, the detection of the radioactive material is a very critical issue to check the nuclear bomb making trial. However, there is the limitation to detect the test effect. So, the other kind of effects can be used. For example, the earthquake of the underground generated the seismic wave which has 2 kinds of waves as primary and secondary waves. Furthermore, the oscillation by the nuclear experiment could significantly affect the residents. In the case of the underground nuclear test to avoid the hazard radioactive material leak to the environment, the earthquake oscillation spread out to wide areas where the civilian damage could be expected. The building would be trembled and sometimes collapsed by the shock wave. Hence, the detection system should be mixed with several kinds of the detection systems as the space satellite and the geological seismic wave counting system.

The nuclear fuel cycle is like the life of the human where the lifetime is circulating pattern from birth to death. However, the repossessing of the nuclear cycle is like the renewal of the material for the different kind of function from peaceful energy production to dangerous bomb manufacturing. So, it is critical to control the nuclear fuel cycle. Currently, the nuclear waste after nuclear power generation is under control in the repository or plant site. However, there are many countries that are suffering from seeking the enteral nuclear waste repository due to the phenomena of the people's objections of Non-In-My-BackYard (NIMBY). Sometimes it is a very serious situation in the nuclear repository selection. It is not easy to persuade the residents to accept the repository in their village. They are not reliable on the construction technology of the repository, which should guaranty of safety for tens of thousands years or hundreds of thousands years. However, it is not easy to prove the reliability of nuclear repository during very long time, because there are many uncertainties in operating the repository. That is to say, the astronomical time is not imaginable in the facility.
The geological uncertainty of the facility building has many kinds of factors. If the asteroid falls down to the site, it could be broken down. Then, the radioactive hazards could leak to the environment and the contaminated material flow away globally. For preparing of this case, much more advanced repository technology is needed to enhance the reliability of the facility. It is popular to investigate on the very tiny material of the nuclear material container where the nano-scopic investigation could produce the innovations of the nuclear waste management in which the molecular behavior of the nuclear material is analyzed of the interaction with the waste container. The nuclear interaction can decide the lifespan of the material which needs the time-proof and water-proof against the underground water.

\section{B. Nuclear safeguards}

There are accounting for and control of nuclear materials [8-10]. The safeguards agreements make the assurance to the NPT require the State (nation) to establish and maintain a national system of explanations and manipulate of nuclear material in its territory, jurisdiction or control. The safeguards system of Euratom meets this function in the case of the European community. Most nations have several critical nuclear tasks to find it to be in their national interest to establish effective means of accounting for and control of nuclear materials in their territories, whether or not they are groups to NPT safeguards agreements with the IAEA.

There are the safeguards measures by the IAEA, which will now be described in more detail. The IAEA nuclear materials accountancy and verification are based on reports submitted by the State System on Accounting for and Control of Nuclear Materials (SSAC) as well as on records kept at facilities in others as well as NPT States. It is the responsibility of the competent national authority to ensure that plant operators comply with the requirements of the safeguards agreement. These requirements have the properand-accurate keeping of records and the timely-andaccurate reporting according to an agreed format. In addition, the national authority should make sure that the capabilities and equipment at nuclear facilities for measuring the quantity and composition of nuclear material are maintained at the level of the latest international or comparable standards. Additionally, the national authorities are responsible for ensuring that IAEA inspectors granted all necessary access to facilities and material and for providing the support they require effectively to discharge their duties. 


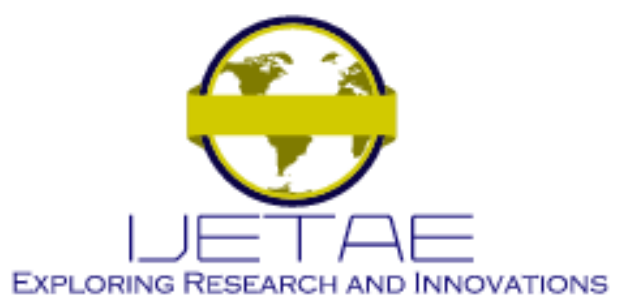

International Journal of Emerging Technology and Advanced Engineering

Website: www.ijetae.com (E-ISSN 2250-2459, Scopus Indexed, ISO 9001:2008 Certified Journal, Volume 11, Issue 12, December 2021)

It means they must also enable and assist IAEA inspectors to apply containment and surveillance measures (e.g. seals, cameras, and other recording devices) at nuclear facilities. The same measure or device is used to meet the requirements of both domestic physical protection measures and IAEA safeguards in several cases.

The main design of the safeguards is made for the material for nuclear explosives to find out whether or not highly enriched uranium (HEU) or plutonium $(\mathrm{Pu})$ is produced in specialized facilities. The construction and misuse of commercial nuclear power reactors is neither the easiest nor the most efficient route to acquiring nuclear material for the manufacture of nuclear explosives. Fuel cycle facilities associated with such reactors, however, might be used in some circumstances to produce nonsafeguarded nuclear material for nuclear explosives. It is, therefore, necessary for all nuclear material in a country's fuel cycle to be safeguarded if the IAEA is to be in a position to give assurances of non-diversion for the State as a whole. The nuclear fuel cycle refers to the system of nuclear installations interconnected by a stream of nuclear material used in the production of nuclear energy. Such a system may consist of uranium mines, ore-processing plants, conversion plants, enrichment plants, fuel fabrication plants, nuclear power reactors, spent fuel storages, reprocessing plants and associated storage. The fuel cycle can be 'closed' in various ways. That is, it is done by recycling of plutonium and uranium through reactors, by re-enriching the uranium recovered as a result of reprocessing, or by using the plutonium in the fast breeder reactor fuel cycle. All these stages taken together are illustrated schematically in Fig. 1. Only a few countries have facilities corresponding to all the installations shown in the figure. In most countries, only part of the fuel cycle exists and in the minimum case, only a power reactor supplied from abroad, or an R\&D laboratory.

Recently, the cyber space has been considered as another area of the economic and technological field where the many activities have been conducted. The nuclear system has similar characteristics of the information transportations including the confidential data of the NPP. If the computer virus invades into the plant, the operation could be affected by the serious computer virus and the system would be failed. If the reactor core is in danger situation, the criticality of nuclear fuel increases to the noncontrollable overpower. The reactor could go to the system failure.
So, the core could be melted in the case of the coolant failure which had happened in previous 3 cases of the Three Mile Island, Chernobyl, and Fukushima accidents, and this situation was the eternal failure of the NPP. Computer based operation system has the weakness in the networking. The internet networking is connected to the external networking. So, it needs to check the computer virus and cure the virus infections by the real-time step. The dynamical investigation is one of the critical issues. However, human couldn't follow the computer networking operations due to the fast processing. In this study, the dynamical modeling is based on the interested time step where the calculation of the simulation is variable following the designed time step. Therefore, the short time step could give much more information to the operator, then the detail simulation results are taken. This kind of the analysis could give the fast reaction to the external terror attacks. That is, the conventional assessment modeling needs many operational data with a long term cycle. However, in the system modeling of this study, the simulation could be performed frequently following the time step, which can construct the wise cyber security system in nuclear facility.

\section{Attacks on Nuclear Power Plants}

It is needed to consider the elements for nuclear security which is different from the accident in NPPs. A nuclear and radiation accident is defined by the IAEA as an event that has led to significant consequences to people, the environment or the facility. Examples include lethal effects to individuals, large radioactivity release to the environment, or reactor core melt [10]. Otherwise, the intentional damage to the nuclear facility can be considered in the scrutiny matters. During last 30 years, there were military air strikes, invasions, occupations, and campaigns [11]. So, terror attacks on the NPPs are included in the security stuffs where the modern nuclear safety concept has included many kinds of aspects on security as well as safety. Otherwise, the nuclear safety had focused on the nuclear accidents which means unwanted malfunctions of the NPPs are very critical factors in operations.

As the tendency of terror attack on the civilian facility has increased, the energy facility has been in the state of the maximum alert, especially for the nuclear facility. It is similar for the terror incident to be detected before the incident such as the conventional accident incidents are not detected easily. 


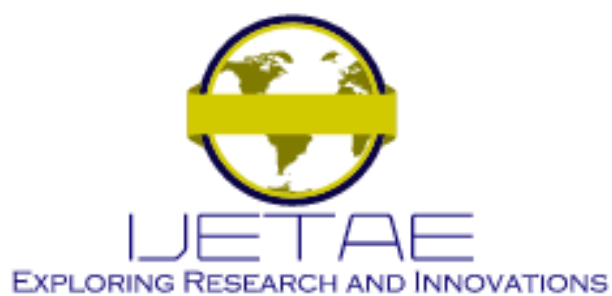

International Journal of Emerging Technology and Advanced Engineering

Website: www.ijetae.com (E-ISSN 2250-2459, Scopus Indexed, ISO 9001:2008 Certified Journal, Volume 11, Issue 12, December 2021)

Considering the past severe accidents as Fukushima, Chernobyl, and Three Mile Island cases, the human factor is one of important factors to analyze the accidents. In most terror incidents, the human portion is top factor in the analysis of the terror incidents, because the terrorist must be involved in any terror cases. So, the classifications of the terrors need to be related to the human actions. A variety of the behaviors could give the clues of the attacks on the NPPs. Especially, the nuclear fuel cycle contains all steps of the nuclear material transportations in which the civilian stages are easily to be attacked by terrorists.

There are quantifications of each stage based on the randomly generated numbers in this modeling. Random sampling is one of estimation methods for the uncertainty based modeling, because the future forecasting has the uncertainty in the simulation study. Therefore, the mathematical calculations of the modeling quantifications are performed by the Monte-Carlo method based analysis, which has been a role of the non-stochastic algorithm in the modeling estimation. Although it is not easy to describe the values of human related elements exactly, the Monte-Carlo algorithm can give the numerical values in the uncertain evaluations. In the results, since it is impossible to show the status of the exact terror attack incident, the values could be analyzed by the relative numbers. So, the importance degrees of the expected cases are shown in which the degree can be considered such as the numbers of the casualty or money. This kind of modeling needs the knowledge of the experts who have experienced in the related job for a long time. The subjective decision making should be based on several facts that are originated for the numerical values incorporated with the random number generations. Even though the values of the results can't reflect the exact terror case or date, the maximum or minimum degree of the possibilities could be obtained by the modeling quantifications. Therefore, the modeling the study is very important, which makes the outline of the study.

\section{System dynamics}

In 1960s, Dr. J. Forrest in Massachusetts Institute of Technology (MIT) made the SD for the quantifications of the systematic situations. The non-linear manipulations of the social and economic system are quantified by mathematically as well as analytically. The complex features in the dynamical scenarios of the system are analyzed by this SD. The SD has been applied for the organizations by the transitions of the time.
$\mathrm{SD}$ is very similar to systems thinking and constructs the same causal loop diagrams of systems with feedback. The $\mathrm{SD}$, however, usually goes further and utilizes simulation to study the behavior of systems and the impact of alternative policies [12]. That is, systems thinking is a kind of the processes of understanding in which the things influence one another within the system. The systems thinking examples include ecosystems where many various elements like sky, air, movement, trees and animals interact together to survive or breed in this world. In case of any organization, the systems consist of people, structures, and processes that work together to make an organization healthy or unhealthy. The systems thinking shows us the tools for solving the management problems, which have been used for over thirty years [13] and are now well established. These ways need the shift way about the performance of an organization. Especially, they require that we move away from looking at isolated events and their causes. This can look at the organization as a system of interacting parts. The dynamic simulation method is introduced using the SD where some computer packages as the Vensim [14], PowerSim [15], and ITHINK [16] have been applied for the quantifications. In this study, the Vensim is used for the simulations [17].

The calculation for the analysis is done by the SD. Dynamical quantification is useful to prepare the incident which would be happen in the future. Interested period of the simulation is performed by the Vensim code system in this study. There are several key features of SD properties. The dynamical behavior of SD is explained as Nonlinearity (A large part of the SD modeling process involves the application of common sense to dynamic problems.), Stock-flow (In SD modeling, it is the principle of accumulation to be raised by dynamic behavior. It is like a bathtub where a flow can be thought of a faucet and pipe assembly that fills or drains the stock.), Feedback (The stocks and flows in real world systems are part of feedback loops.) and Time paths (Most important thing of the SD modeling is the dynamic behavior of systems, where the operator tries to identify the patterns of behavior exhibited by interested system variables, and then builds a model with the characteristics of patterns.).

In the applications of the SD, the non-linear and complex algorisms are used. The nuclear accident is one of good examples where unexpected scenario could go to the reactor system failure. Although there are multiple defense protection systems for the anticipated nuclear accidents. However, it doesn't work properly. 


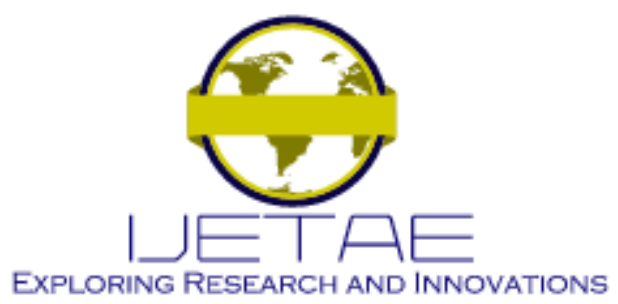

International Journal of Emerging Technology and Advanced Engineering

Website: www.ijetae.com (E-ISSN 2250-2459, Scopus Indexed, ISO 9001:2008 Certified Journal, Volume 11, Issue 12, December 2021)

For example, in the case of the Fukushima disaster, the hydrogen explosion was the main cause of the plant failure, in which the hydrogen produces in the nuclear fission process of the plant operations. If it was pilfered out using the valve opening, the explosion was not happened. There was more than one day until the hydrogen explosion. The operator couldn't make a decision to open the value in order to take the permission of prime minster. Once the value was open, the radioactive material would leak to the environment without control. So, the operator seems to avoid the legal responsibility of radioactive material leak to environment using the permission of prime minister. This situation couldn't calculate using the conventional safety analysis modeling, because the operator is scheduled to open the value in the situation. But, the real situation was happened differently. In addition, the Fukushima site is located on the seashore. So, there was a chance to use seawater to cool down the reactor core. But, the plant operators didn't use the seawater to avoid the damage of the reactor core by the seawater which contains the salt compound. If the seawater was injected into the core, the core was cooled down and the temperature would be stabilized. So, it is not easy for this kind of human mistake to be modelled using the conventional system modeling where the probabilistic risk analysis (PRA) uses the probability based quantifications for the system modeling. The probability has the characteristics of the linear algorithm of the system modeling comparing to the nonlinear logics like the fuzzy set or neural network algorithm. Even though the probability is tractable of the simulations in the physical and social matters for the numerical quantifications.

SD can use the complex characteristics of nonlinearity of the human related tasks. The terror usually happens by terrorists who have their purpose like political, social, economic, and some reasons. Therefore, terror should be analyzed by the complexed human mind where the rational and emotional stuffs are incorporated each other. In the case of the unwanted nuclear accident, the system failures are major issues of the accident analysis. However, the terror incidents are produced by the terrorist. So, it is needed to use the non-linear algorithm for describing complex based event scenarios. It is still impossible to see the brain in order to know the mind of the terrorist. Therefore, it is needed to find the tendency of the terror purposes. The data mining is one of the data processing technologies where the pattern of the data could give the hint of the behaviors.
In this skill, the information technology (IT) should be applied to seek the potential terrorist that the suspicious activity is analyzed from the experienced data of the reported persons for some networks. The networking concept is frequently utilized in the IT for the communications in the society where the security is designed by management of the information. Non-linear complex algorithm of SD can show the interaction activities of the tasks using the dynamical manners. The time sequence is easily used by the time step where the detail descriptions of the suspicious activity are shown in the dynamic simulations. The analysis results are obtained by the relative values in the designed graph where the comparative outputs are showing the degree of the terror incident possibility. So, this graph can show the operator can know easily the situations of the incidents, which can be calculated by the real-time step due to the computer programming in the personal computer. In the current system, the probability based analysis is a regulation in the NPP construction, where the real-time analysis is not able to be performed. So, the SD analysis is much more powerful in the security analysis.

\section{E. Modeling}

Fig. 2 shows the nuclear fuel cycle for SD simulation which is made by the nuclear fuel cycle in Fig. 1. Fig. 3 is the Threats by the SD method. This is a case of stock-flow case where the Rate has a single arrowhead, which indicates the direction that material can flow (the Rate can only increase the Level). This is only a diagram of the equation which governs the direction in a simulation model that material can flow. When the meaning of the feedback is plus, the feedback value, Damages, is added to the Activity Initiations. Hence, the Threats is calculated by,

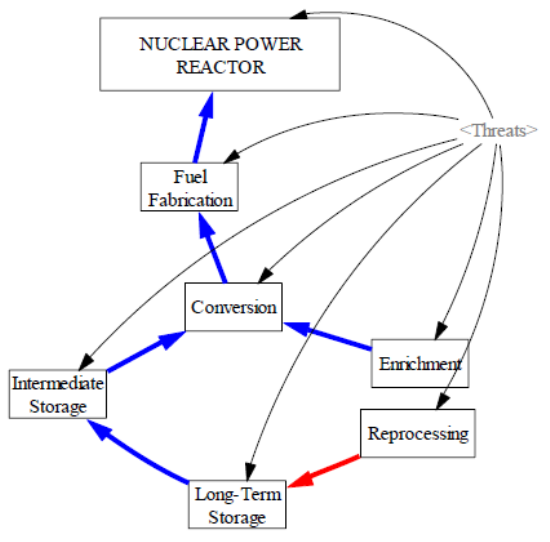

Fig. 2 Nuclear fuel cycle by SD. 


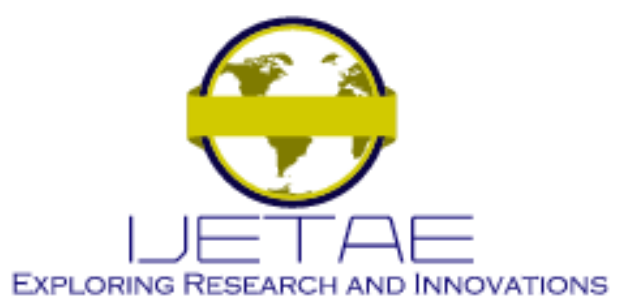

International Journal of Emerging Technology and Advanced Engineering

Website: www.ijetae.com (E-ISSN 2250-2459, Scopus Indexed, ISO 9001:2008 Certified Journal, Volume 11, Issue 12, December 2021)

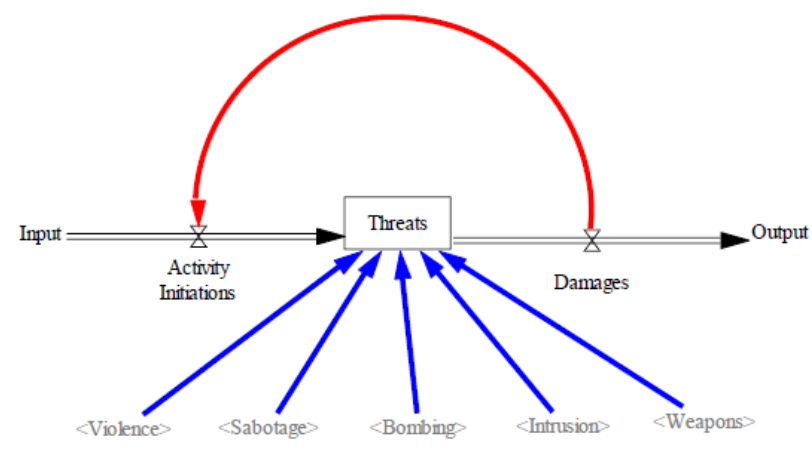

Fig. 3 Threats by SD.

(Activity Initiations -Damages -Violence -Sabotage Bombing -Intrusion -Weapons)

Activity Initiations is,

RANDOM UNIFORM $(0,1)+$ Damages

Damages is,

$$
\text { RANDOM UNIFORM(0, 0.8) }
$$

Where the values are uniform random number distributions as the value between 0 and 1 as the default seed as a value of 4,487,556 which is a function of Vensim code system in the case of the RANDOM UNIFORM ( 0 , 1). Similarly, RANDOM UNIFORM $(0,0.8)$ means the values are uniform random number distributions as the value between 0 and 0.8 . Table 1 shows the values of each factor. Each value has the subjective quantity which is decided by expert's judgment. If the range of the random number is lower near 0 , the possibility of the incident is lower comparatively.

TABLE I

VALUES OF FACTORS

\begin{tabular}{|l|l|l|}
\hline \multicolumn{1}{|c|}{ Factor } & \multicolumn{1}{c|}{ Sub-factor } & \multicolumn{1}{c|}{ Value } \\
\hline \multirow{5}{*}{ Violence } & Juvenile delinquency & RANDOM UNIFORM $(0,1)$ \\
\cline { 2 - 3 } & Family problems & RANDOM UNIFORM $(0,0.7)$ \\
\cline { 2 - 3 } & Antisocial personality & RANDOM UNIFORM $(0.3,1)$ \\
\cline { 2 - 3 } & Violence history & RANDOM UNIFORM $(0,0.8)$ \\
\cline { 2 - 3 } & Unmarried & RANDOM UNIFORM $(0,0.6)$ \\
\hline \multirow{5}{*}{ Sabotage } & Payment & RANDOM UNIFORM $(0,1)$ \\
\cline { 2 - 3 } & Emotion & RANDOM UNIFORM $(0.3,1)$ \\
\cline { 2 - 3 } & National economy & RANDOM UNIFORM $(0,0.8)$ \\
\hline \multirow{3}{*}{ Intrusion } & Terror organization & RANDOM UNIFORM $(0,1)$ \\
\cline { 2 - 3 } & Theft from troops & RANDOM UNIFORM $(0,0.6)$ \\
\cline { 2 - 3 } & Home-made bomb & RANDOM UNIFORM $(0.3,1)$ \\
\hline \multirow{3}{*}{ Weapons } & Illegal invasion & RANDOM UNIFORM $(0,0.8)$ \\
\cline { 2 - 3 } & Security failure & RANDOM UNIFORM $(0.2,1)$ \\
\cline { 2 - 3 } & Militay supply & RANDOM UNIFORM $(0,0.9)$ \\
\cline { 2 - 3 } & International group & $0.3,1)$ \\
\hline
\end{tabular}

In addition, as the range of the random number is wider, the uncertainty of the event happening is larger. So, the range of the random number generation can reflect the decision making of the expert. Fig. 2 is the Nuclear fuel cycle by SD. There is some related modeling of the simulations. In Fig. 3, the Damages goes to the Activity Initiations as feedback loop, which means that the Threats based Damages effects on the Activity Initiations. Fig. 4(a) is the Violence by SD. The sub-factors are data from the Risk Factors for General Violence in Table 2 [18]. These factors are modified in the study for the modeling. In the social sciences, most of the risk factor research has focused on predicting the general violence risk. General violence risk means the likelihood that an individual might engage in any aggressive act toward anyone over a specified period of time. It is certain that there is posed in terrorist threat assessments. General people will not make any terror, which have a collection of general violence risk factors. In addition, many known terrorists including some field leaders of the 9-11 attacks showed many general violence risk factors, even though they were actively preparing to engage in acts of terrorism. Similarity, Fig. 4(b) is the Sabotage by SD. This is composed of 3 sub-factors. This is related to worker's right of the company. The security of the system including the company and organization is related to labor conditions. Fig. 4(c) is the Bombing by SD. This factor focuses on stealing the skill of manufacturing of bomb. Fig. 4(d) is the Intrusion by SD. Fig. 4(e) is the Weapons by SD, which is to take the any kind of weapon.

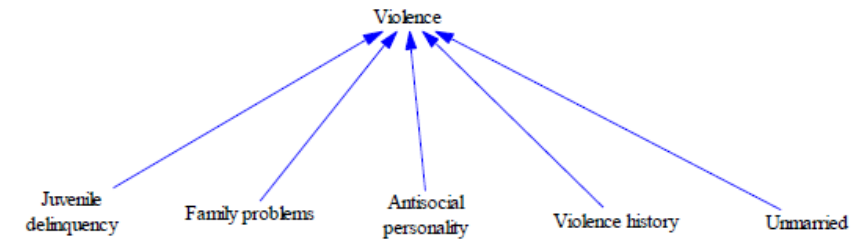

(a)

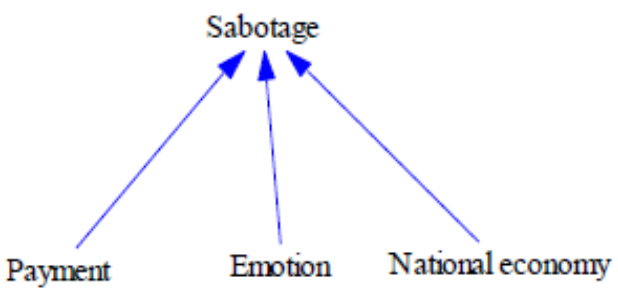

(b) 


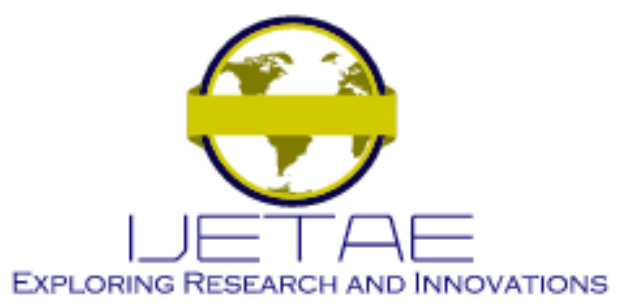

International Journal of Emerging Technology and Advanced Engineering

Website: www.ijetae.com (E-ISSN 2250-2459, Scopus Indexed, ISO 9001:2008 Certified Journal, Volume 11, Issue 12, December 2021)

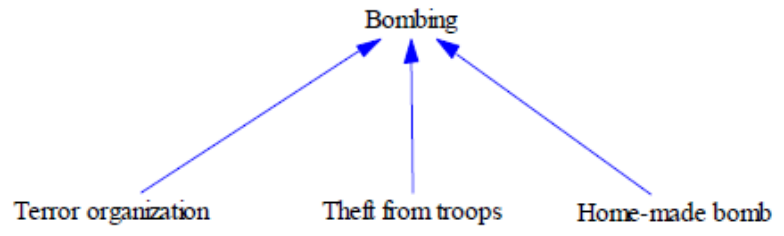

(c)

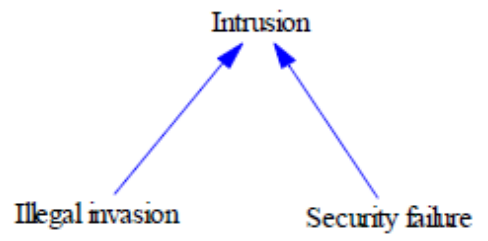

(d)

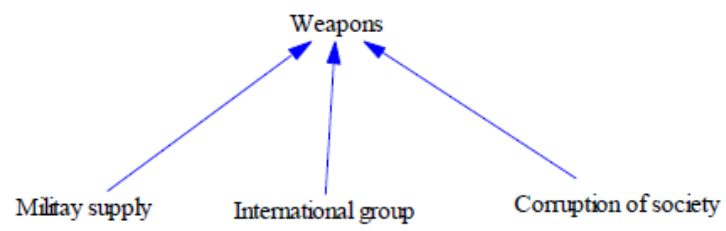

(e)

Fig. 4 SD modeling (a) Violence, (b) Sabotage, (c) Bombing, (d) Intrusion, and (e) Weapons.

\section{TABLE III}

RISK FACTORS FOR GENERAL VIOLENCE

\begin{tabular}{|c|c|}
\hline Factor & Sub-factor \\
\hline Violence & Juvenile delinquency \\
\cline { 2 - 3 } & Family problems \\
\cline { 2 - 3 } & Antisocial personality \\
\cline { 2 - 2 } & Hospital admissions \\
\cline { 2 - 2 } & Violence history \\
\cline { 2 - 2 } & Institutional adjustment \\
\cline { 2 - 2 } & Adult criminal history \\
\cline { 2 - 2 } & Unmarried \\
\hline
\end{tabular}

\section{RESULTS}

There are graphs of results for the simulations. Fig. 5 shows the quantification result for Threats. The values oscillate around 0.75 , as it is seen clearly. This means the Threat factor are changeable by time flow. These values are compared by the comparative quantities.
So, the meaning of 0.75 is not exact physical or social meaning and it is reasonable to compare each other. It is effective to prepare for possible terror attacks following the numeric values by dynamical status. One can estimate the possibility of the potential terror incident by the comparative values among the results. A comparison is a best method to make the planning in each time in the designed period. In addition, there is a graph of the security of the nuclear fuel cycle which is related to NPP in Fig. 6. The value is higher, when the security is in worse situations. The highest value is 62.33 in $59^{\text {th }}$ month and the lowest value is 0.72 in $120^{\text {th }}$ month. The difference between two values is 86.57 times. That is the possibility of terror incident is higher as 86.57 times. Hence, the maximized guard planning could be formed by the management of the authority in the nuclear facility.

The results could be modified following the weighted factor like the specified social matters like the economy, culture, policy and so on. The applications can change the algorithm of the program, which could be done easily for the better solutions. The manipulations are decided by some data and the expert's intuition based decisions.

\section{CONCLUSIONS}

The nuclear fuel cycle process is assessed by the dynamical analysis of complex algorithm. The final focusing point is on the NPP where the steps of the nuclear fuel cycle are related by connections of the event flow line.

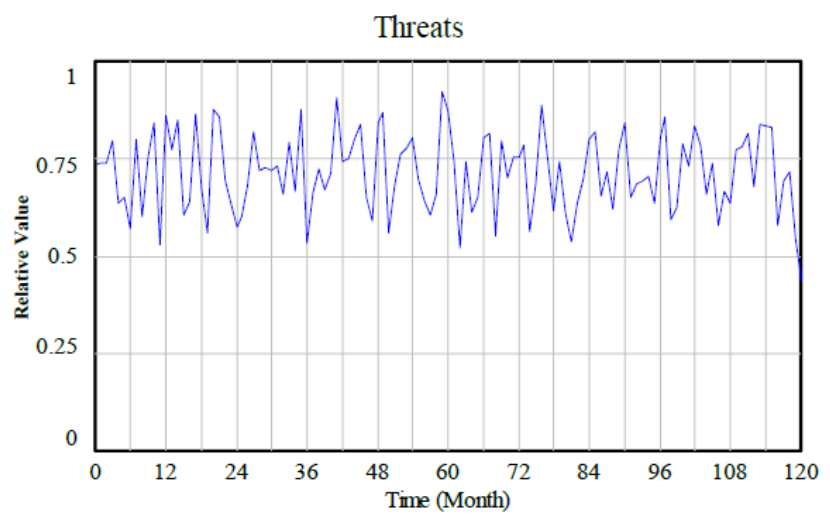

Threats : Current

Fig. 5 Simulation result for Threats. 


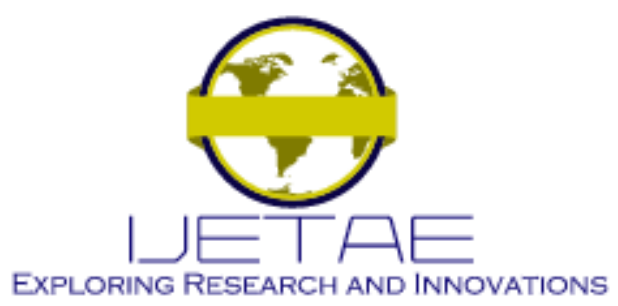

International Journal of Emerging Technology and Advanced Engineering

Website: www.ijetae.com (E-ISSN 2250-2459, Scopus Indexed, ISO 9001:2008 Certified Journal, Volume 11, Issue 12, December 2021)

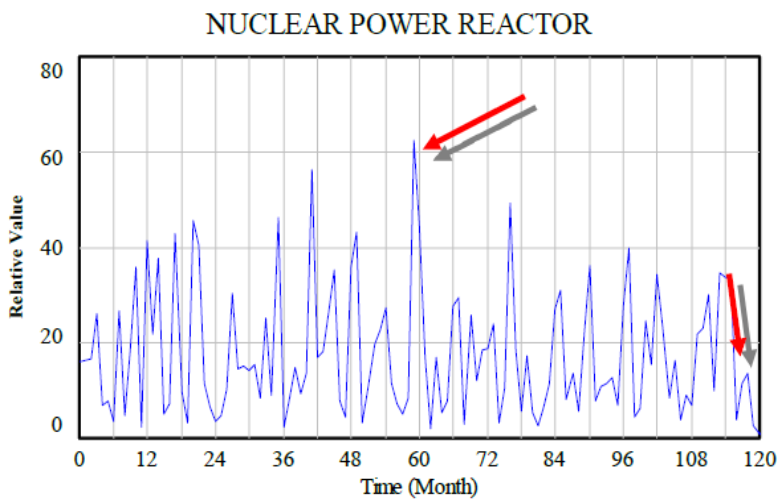

NUCLEAR POWER REACTOR : Current

Fig. 6 Simulation result for Nuclear Power Reactor.

Non-linearity of the nuclear fuel cycle is modeled with the SD where the data feedback and stock-flow can give the tractable analysis of the interested issue where the complex meaning of the nuclear stuff can give the operator the security situations by time step manner including modifications of the input data values. There are several key issues of this study.

- The dynamical simulation of the nuclear fuel cycle is performed.

- Security incorporated with safeguards is considered.

- 10 years' analysis could be extended to lifetime of 60 years for NPP.

- Expert's judgments are shown by the values of the basic factors.

- One can prepare for the danger situation of future in security.

There are specific elements which go to the Threats analysis. Using this study, the other companies in the industry are applicable in the matter of security which is related to terror case including the non-profitable movement by workers. The financial loss by unexpected or expected incidents can produce many damages. Therefore, the numerical estimation can make the detail preparation for the future event. Although, there is not an exact prediction, the caution of the security increases. Data quantification could be done by the real-time manner which is different from the conventional algorithm, PRA, a linear data processing by probability manipulations.

It is not easy to find the difference between security and safety. Security has the meaning of normal operations without intended violence or illegal attack. Therefore, the security is different from the accident which has less meaning in legal matter consideration.
Accident happens usually by unexpected sequences without terrorist or criminals. However, the results of the terror and accident are similarity to affect the function and facility devastatingly. Hence, it is important to consider the nuclear facility in the aspect of the security as well as safety. The stable operation of NPP is accomplished by these two standards of preparing for terror and accident. Basically, the terror and accident should be avoidable incidents in the NPPs. However, if there is an accident or terror, it important to manage the recovery as soon as possible where the reactor core should be protected by all efforts. So, the situation analysis should be done urgently and give the information to the operators in the plant site.

In addition, there are several applications in the other industries. Although the importance of the nuclear industry is modeled in this work, there are some less secured matters such that the traffic and food industries could be examined by the SD methods. The airplane control field should take non-linear algorithm due to the complexity of the flight accident scenario. So, in this work, the complex algorithm was used for the dynamical manners for the quantifications. The study object is able to changeable following the applicability of the logic. In the developing of the SD modeling, the forecasting of the event is easily able to be described in the simulations where the graphic based drawing and the Monte-Carlo based random sampling is used for the modeling quantifications. So, the results are obtained by the comparative values where the maximum value shows the higher incident possibility incorporated with the uncertainty. So, the data quantified analysis can give the easy explanation of the modeling results.

\section{REFERENCES}

[1] US NRC. (2015). Nuclear Security and Safeguards Analysis, <http://www.nrc.gov>.

[2] Perninge, M., Lindskog, F., \& Soder, L. (2012). Importance Sampling of Injected Powers for Electric Power System Security Analysis. IEEE Trans. Power Syst. 27, 3-11.

[3] Trehan, N.K. (2000). Impact of system security in an open market on nuclear power generating stations. IEEE Power engineering society summer meeting. 2367-2371.

[4] Chen, Q., \& McCalley, J.D. (2005). Identifying high risk n-k contingencies for online security Assessment. IEEE Trans. Power Syst. 20, 823-834.

[5] Jun, E., Kim, W., \& Chang, S.H. (2009). The analysis of security cost for different energy sources. Appl. Energy. 86, 1894-1901.

[6] Salameh, M.G. (2003). The new frontiers for the United States energy security in the $21^{\text {st }}$ century. Appl. Energy. $76,135-44$.

[7] US NRC. (2011). Stages of the Nuclear Fuel Cycle, <http://www.nrc.gov>. 


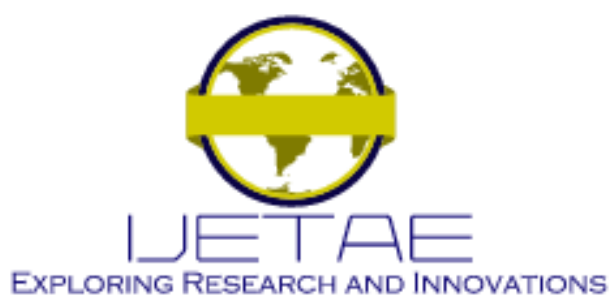

International Journal of Emerging Technology and Advanced Engineering

Website: www.ijetae.com (E-ISSN 2250-2459, Scopus Indexed, ISO 9001:2008 Certified Journal, Volume 11, Issue 12, December 2021)

[8] IAEA. (2004). Guidelines and Format for Preparation and Submission of Declarations Pursuant to Articles 2 and 3 of the Model Protocol Additional to Safeguards Agreements. IAEA Services Series 11.

[9] IAEA. (2005). ISSAS Guidelines Reference Report for the IAEA SSAC Advisory Service. IAEA Services Series 13.

[10] IAEA. (2008). AEN/NEA/ International Nuclear and Radiological Events Scale Users' Manual, 2008 Edition. Vienna, Austria: International Atomic Energy Agency, 184.

[11] Sovacool, B.K. (2011). Contesting the Future of Nuclear Power: A Critical Global Assessment of Atomic Energy. World Scientific. 192.
[12] System Dynamics Society. (2021). System Dynamics, Littleton, MA, USA

[13] Forrester, J.W. (1961). Industrial Dynamic. Productivity press.

[14] Vensim. (2016). Ventana Systems, Inc., Harvard, MA, USA.

[15] PowerSim. (2021). Powersim Software, Nyborg, Norway.

[16] ITHINK Software. (2021). ISEE Systems, Inc., Lebanon, NH, USA.

[17] Woo, T.H. (2015). Social impact theory basedmodeling for security analysis in the nuclear fuel cycle. Kerntech. 80(1), 70-75.

[18] Borum, R. (2004). Psychology of Terrorism. Tempa: University of South Florida. 